\title{
Use of the Analytical Hierarchy Process to Determine the Steering Direction for a Powered Wheelchair
}

\author{
Malik Haddad ${ }^{1}$, David Sanders ${ }^{1}$, Mohamad Thabet ${ }^{1}$, Favour Ikwan ${ }^{1}$ and Alexander \\ Gegov 1 \\ ${ }^{1}$ University of Portsmouth, Portsmouth, PO1 3DJ, UK \\ david.sanderseport.ac.uk
}

\begin{abstract}
The Analytical Hierarchy Process (AHP) is utilized to propose a driving course for a powered-wheelchair. A safe route for a wheelchair is proposed by a decision-making system that aims to avoid obstacles. Two ultrasonic transceivers are fitted onto a wheelchair. The area in front of a wheelchair is segmented to left and right zones. The system inputs are distance to an object from the midpoint of the chair, distance to an object from the left of the chair and distance to an object from the right of the chair. The resulting route is a blend between a provided direction from a user's input device and a proposed direction from the decision-making system that steers a powered-wheelchair to safely avoid obstacles in the way of the wheelchair. The system helps a disabled user to navigate their wheelchair by deciding on a direction that is a compromise between a direction provided by the sensors and a direction desired by the driver. Sensitivity analysis investigates the effects of risk and uncertainty on the resulting directions. An appropriate direction is identified but a human driver can over-ride the decision if necessary.
\end{abstract}

Keywords: Analytical Hierarchy Process, AHP, Wheelchair, Direction.

\section{$1 \quad$ Introduction}

A Multi Criteria Decision Making (MCDM) approach is presented that helps with the driving of a powered-wheelchair. Ultrasonic sensors are considered to provide information about the surroundings of a wheelchair. The new decision-making system then assists disabled drivers to drive safely. A driver provides a desired route and sensors generate an alternative route. Intelligent mixing of the two routes generates a new route. The desired route is modified depending on sensor readings [1-11] to help disabled drivers.

Extensive research has been conducted on powered-wheelchair driving and navigation [12-17]. Outcomes have often been local, without global application. Approaches to avoid obstacles have been studied [18] that considered sensors providing local information [19].

The use of MCDM with sensors is presented. It can successfully drive the motors connected to the driving wheels of a powered wheelchair. The architecture promptly 
detects obstacles ahead, manages to turn in the desired direction specified by a human driver, and avoids obstacles.

A best compromise route is provided that evade obstructions. A joystick controls direction and speed and then a MCDM system modifies the route if required. The desires of a driver are weighted against distance to nearby obstacles.

The wheelchair considered in this research had two large driving wheels each separately connected to a driving motor. Direction and speed were achieved by providing the required power to each motor. A driver was able to drive their chair by varying electrical current to the two motors.

Many researchers presented systems used to avoid obstacles [20], for example: infrared [21], ultrasonics [22] and structured lighting [23]. Global systems provided uncoordinated outcome inside buildings [24] but local systems were more successful, including: ultrasonics [25-28], gyroscopes, odometers or tilt sensors. Ultrasonic sensors were used because they were simple, affordable and reliable [28].

The sensors used in this research were the same as the sensors described in [29]. They were fitted under the footrests of the wheelchair [30]. Distance to obstacles were measured by calculating the flight time required for pulses to be reflected back from objects [30]. If no obstacle was sensed then detection ranges could be tuned by increasing the length of the ultrasonic pulses until an object was sensed.

The area in front of a wheelchair was segmented into a left zone and right zone. A grid was then placed onto them. The grid consisted of three components: VERY CLOSE, CLOSE and FAR-OFF. Transceiver envelopes over-lapped so that a center column in the grid signified both left and right sensors detecting an object. Any obstacle in front of the wheelchair was labeled as either VERY CLOSE, CLOSE or FAR-OFF.

Section II describes MCDM. Then Section III explains testing undertaken and presents some results. A short discussion is included in Section IV and some conclusions are presented in Section V.

\section{MCDM and AHP}

MCDM methods are often considered as reliable decision-making methods that produced a systemic and straight forward approach to improve objectivity and generate results with reasonable satisfaction [31]. MCDM help in solving real-world problems with multiple conflicting criteria, and they produce a suitable solution even when faced with several possible scenarios that incorporated risk, uncertainty or fuzziness [32]. This is the first time this type of method has been applied to a powered-wheelchair application.

The Analytical Hierarchy Process (AHP) is a method based on applying pairwise judgements amongst choices with respect to each criterion and then coherently aggregating them to provide an overall weighting for each choice with respect to all criteria. Criteria weights indicated their relative significance. AHP used the eigenvalue method [33], where a consistent matrix with known priorities was created and a comparison of choices $\mathrm{i}$ and $\mathrm{j}$ is given by $\mathrm{p}_{\mathrm{i}} / \mathrm{p}_{\mathrm{j}}$. The comparison matrix is multiplied by the priority vector $\vec{p}$ : 
$A \cdot \vec{p}=n \cdot \vec{p}$

Where:

$\vec{p}$ : Priority vector.

$n$ : Matrix dimension.

A: Comparison matrix.

Ishizaka and Labib [34] provided the following steps for a decision-making process that used AHP:

- Modelling of a problem.

- Conduct pairwise comparisons.

- Identify qualitative and quantitative judgments scales.

- Evaluation of local weights

- Check for consistency.

- Evaluation of global weights using (2).

$P_{i}=\sum_{j} W_{j} \cdot l_{i j}$.

Where:

$P_{i}$ : global weight of the choice $i$.

$w_{j}$ : weight of the criterion $j$.

$l_{i j}$ : local weight.

- Sensitivity analysis.

AHP aim at helping decision makers in reaching a suitable decision that corresponded to the global goal of the problem as well as their aims and their understanding of problems. The next section describes testing.

\section{$3 \quad$ Testing}

The new system inputs were: Distance to an object from the midpoint of the chair $\left(D_{c}\right)$, Distance to an object from the left of the chair $\left(D_{1}\right)$, Distance to an object from the right of the chair $\left(D_{r}\right)$.

If no object was sensed in any direction then Distance was set to one. Three setups are described as a powered-wheelchair moved in a setting with some boxes as obstructions.

- $\quad$ Setup 1: No boxes in the surrounding (Point A in Fig. 1).

- Setup 2: Box spotted to the right (Point B in Fig. 1).

- Setup 3: Box spotted to the left (Point C in Fig 1).

Three choices were weighted: Move-Forward, Move-Right and Move-Left. Each choice was given a weight and these are shown in Table 1 as a "decision matrix". 


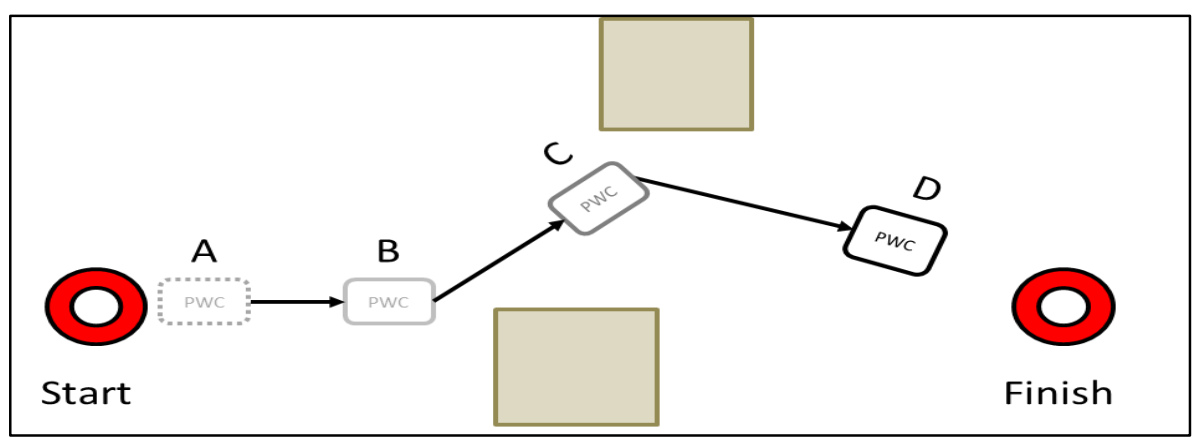

Fig. 1. Powered wheelchair driving through an environment with some cardboard boxes as obstacles.

Table 1. Decision matrix for powered wheelchair.

\begin{tabular}{|c|c|c|c|}
\hline $\begin{array}{ll}\text { Choice } & \text { Criteria } \\
\end{array}$ & $\mathrm{D}_{1}$ & $\mathrm{D}_{\mathrm{c}}$ & $\mathrm{D}_{\mathrm{r}}$ \\
\hline Move left $\left(\mathrm{A}_{1}\right)$ & 0.5 & 0.25 & 0.167 \\
\hline Move forward $\left(\mathrm{A}_{2}\right)$ & 0.333 & 0.5 & 0.333 \\
\hline Move right $\left(\mathrm{A}_{3}\right)$ & 0.167 & 0.25 & 0.5 \\
\hline
\end{tabular}

The area in front of a wheelchair was segmented to left and right zones. If no object was detected $D_{l}, D_{c}$ and $D_{r}$ were fixed to 1 . If the right transducer sensed an object and the left transduce did not then $D_{1}$ was fixed to 1 and $D_{c}$ and $D_{r}$ were evaluated using (3) and (4).

$$
\begin{aligned}
& D_{c}=D \cos (\alpha) \\
& D_{r}=D \sin (\alpha)
\end{aligned}
$$

Where: $\mathrm{D}=$ Distance between the wheelchair and an object; $\alpha=$ Angle were the object was sensed.

If the left transducer sensed an object and the right transduce did not then $\mathrm{D}_{\mathrm{r}}$ was fixed to 1 and $D_{c}$ and $D_{1}$ were evaluated using (3) and (5).

$$
D_{l}=D \sin (\alpha)
$$

Where: $\mathrm{D}=$ Distance between the wheelchair and an object; $\alpha=$ Angle where the object was sensed.

Setup 1 (point A in Fig. 1): The powered-wheelchair began moving, nothing was sensed, Distances were all fixed to 1 . AHP was employed with three choices and three criteria being considered. AHP yielded a ranking of choices: $A_{2}>\left(A_{1}=A_{3}\right)$. Global weights for choices were: $\mathrm{A}_{1}=0.306, \mathrm{~A}_{2}=0.389$ and $\mathrm{A}_{3}=0.306$. The global weights were expressed as vector magnitudes as shown in Fig. 2 and the overall route yielded from AHP was evaluated using vector algebra and shown as a thick black line in Fig.3. 


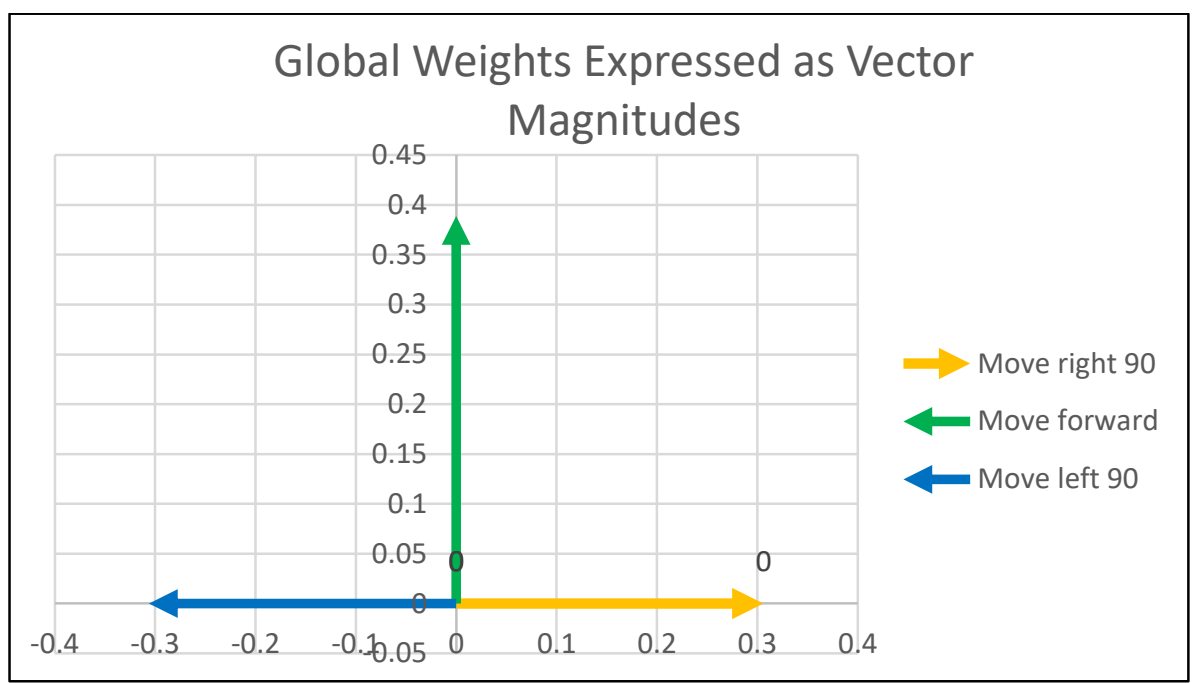

Fig. 2. Global scores of choices expressed as vector magnitudes, Setup 1: no boxes were sensed.

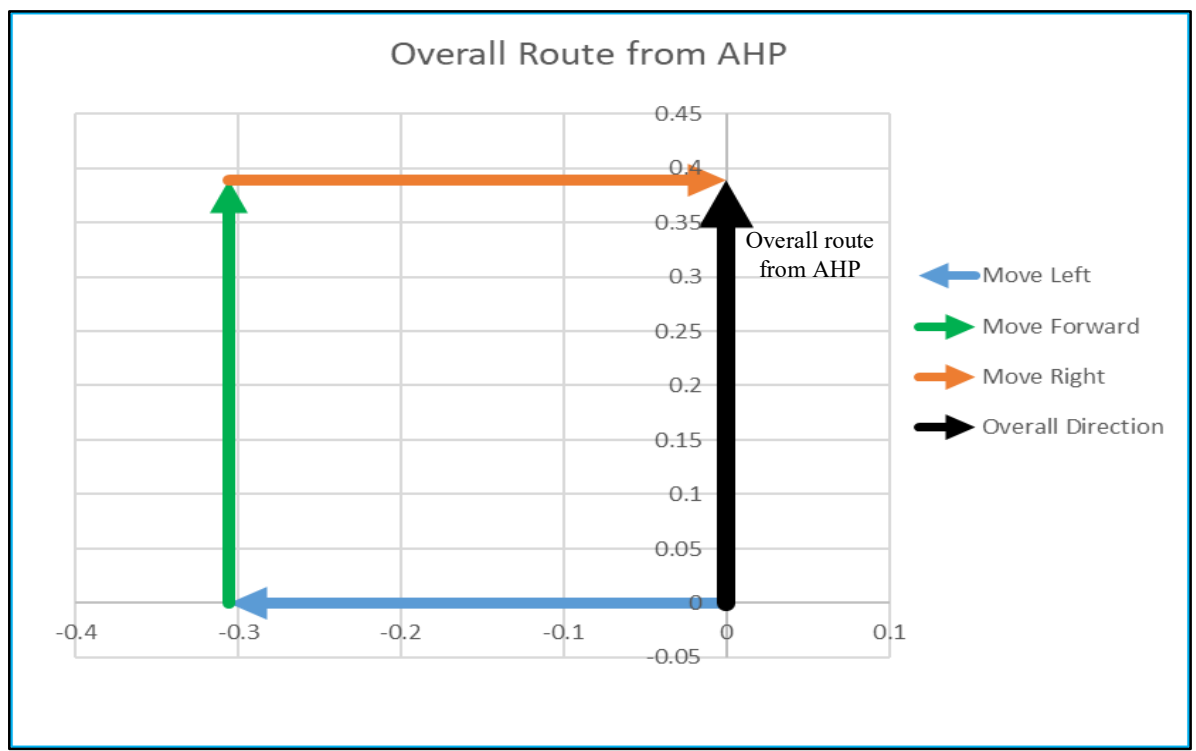

Fig. 3. Overall route yielded from AHP for Setup 1.

Sensitivity analysis was applied to assess the stability of AHP results if risk and uncertainty would affect criteria weights. The smallest changes needed to alter the results were evaluated. Table 2 shows the results where N/F stands for a non-feasible value where $\pm 100 \%$ modification to a criterion value did not alter the result. 
Table 2. Minimum percentage change needed in criteria weights to alter the outcome of AHP, Setup 1, no boxes were sensed.

\begin{tabular}{ll}
\hline Criterion name & Minimum percentage change \\
\hline$D_{1}$ & $\pm 0.1 \%$ \\
$D_{c}$ & $\mathrm{~N} / \mathrm{F}$ \\
$D_{\mathrm{r}}$ & $\pm 0.1 \%$
\end{tabular}

Sensitivity analysis revealed that a $0.1 \%$ modification in $\mathrm{D}_{1}$ or $\mathrm{D}_{\mathrm{r}}$ could alter the route of the powered-wheelchair. $0.1 \%$ rise in $\mathrm{D}_{1}$ or $0.1 \%$ reduction in $\mathrm{D}_{\mathrm{r}}$ caused the wheelchair drive ahead with a small angle to the left, a $0.1 \%$ reduction in $\mathrm{D}_{1}$ or a $0.1 \%$ rise in $\mathrm{D}_{\mathrm{r}}$ made the wheelchair drive ahead with a small angel to the right.

Setup 2 (Point B in Fig. 1): The powered-wheelchair moved ahead, where a box was positioned to the right of the wheelchair. Sensors detected the box shown at point B in Fig. 1. The obstacle was 0.5 meters away at an angle of $45^{\circ}$ as shown in Fig. 4.

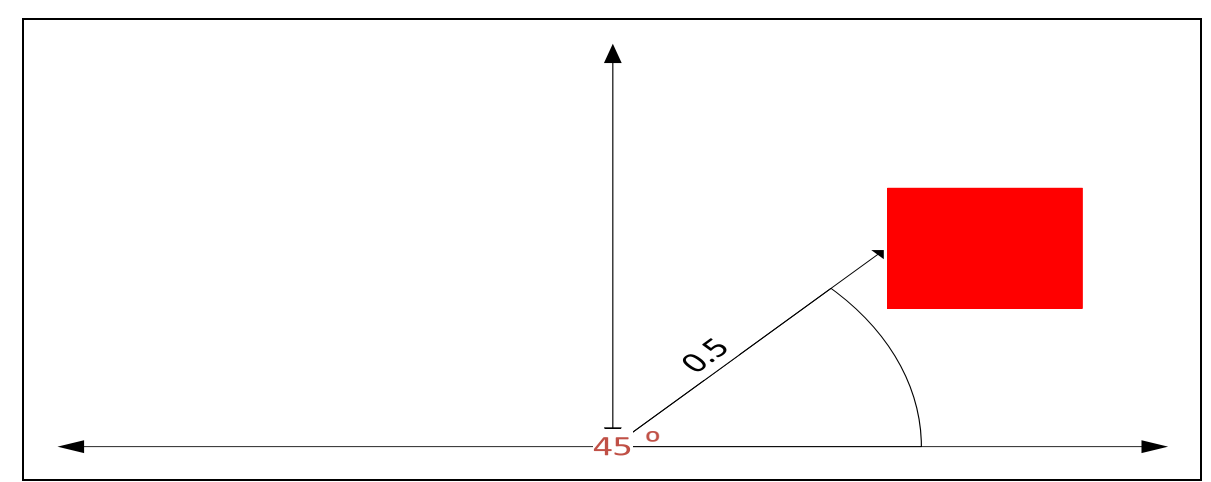

Fig. 4. Setup 2: Box sensed to the right.

$D_{1}$ was fixed to 1 since the left transducer detected nothing. $D_{c}$ and $D_{r}$ were evaluated using (3) and (4).

AHP was employed with three choices and three criteria being considered. AHP yielded a ranking of choices: $A_{1}>A_{2}>A_{3}$. Global weights of choices were: $A_{1}=0.379$, $\mathrm{A}_{2}=0.368$ and $\mathrm{A}_{3}=0.253$. The global weights were expressed as vector magnitudes as shown in Fig. 5 and the overall route yielded from AHP was evaluated using vector algebra and shown as a thick black line in Fig. 6. 


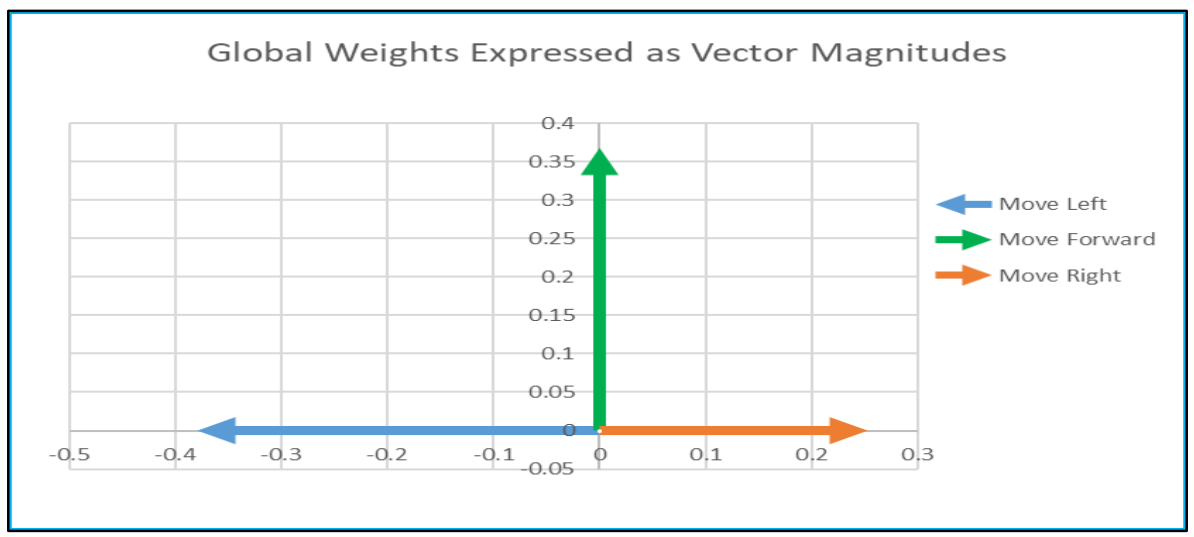

Fig. 5. Global scores of choices expressed as vector magnitudes, Setup 2: box sensed to the right.

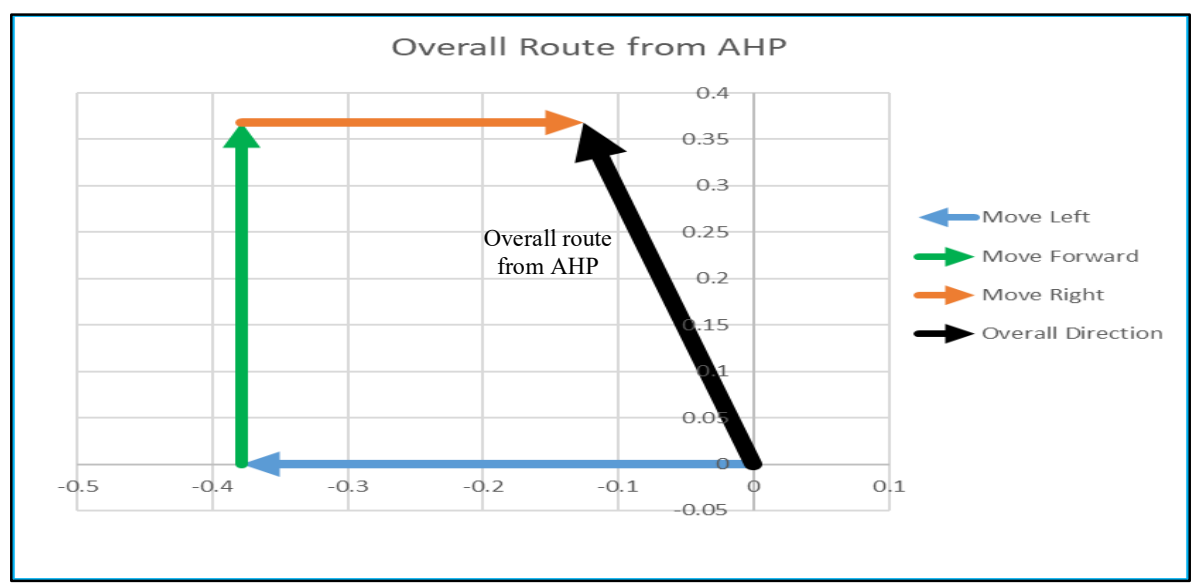

Fig. 6. Overall route yielded from AHP for Setup 2.

Sensitivity analysis was applied to assess the stability of AHP results if risk and uncertainty would affect criteria weights. The smallest changes needed to alter the results were evaluated. Results are shown in Table 3.

Sensitivity analysis identified the effect of change in $D_{r}, D_{c}$ and $D_{1}$ on the overall route of the wheelchair. A $5.81 \% \%$ reduction in $\mathrm{D}_{1}$, a $19.32 \%$ rise in $\mathrm{D}_{\mathrm{c}}$ or a $21.59 \%$ rise in $\mathrm{D}_{\mathrm{r}}$ caused the wheelchair to drive ahead and left with an angle of $134^{\circ}$.

Table 3. The minimum percentage change needed in criteria weights to alter the outcome of AHP, setup 2: 1 box sensed to the right.

\begin{tabular}{ll}
\hline Criterion name & Minimum percentage change \\
\hline$D_{1}$ & $-5.81 \%$ \\
$D_{c}$ & $19.32 \%$ \\
$D_{\mathrm{r}}$ & $21.59 \%$
\end{tabular}


Setup 3 (Point C in Fig.1): The powered-wheelchair moved ahead where a box was positioned to the left of the wheelchair. Sensors detected the box at point C in Fig. 1. The obstacle was 0.2 meters away at an angle of $30^{\circ}$ as shown in Fig. 7.

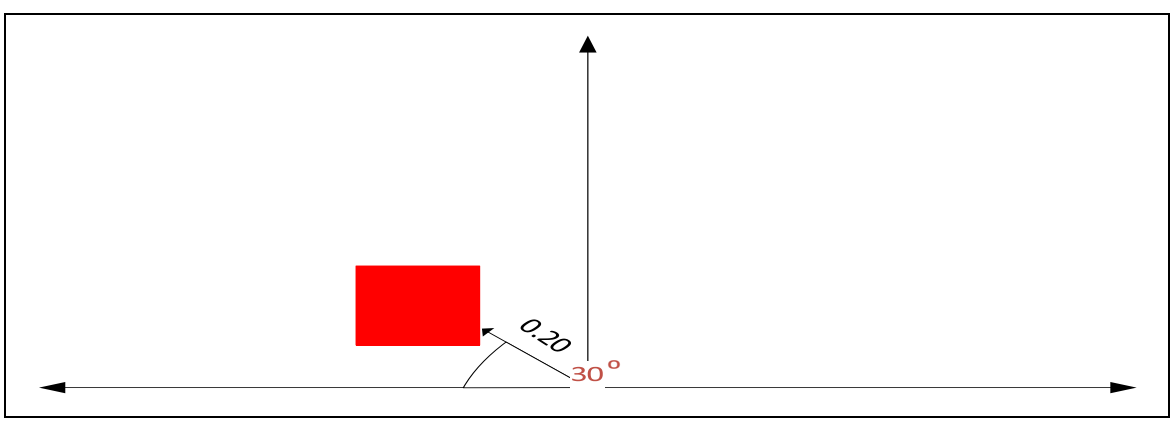

Fig. 7. Setup 3: Box sensed to the left.

Since the right transducer detected nothing $D_{r}$ was fixed to $1, D_{c}$ and $D_{1}$ were evaluated using (3) and (5).

AHP was employed with three choices and three criteria being considered. AHP yielded a ranking of choices: $A_{3}>A_{2}>A_{1}$. Global weights of choices were: $A_{1}=0.204$, $\mathrm{A}_{2}=0.368$ and $\mathrm{A}_{3}=0.44$. The global weights were expressed as vector magnitudes as shown in Fig. 8 and the overall route yielded from AHP was evaluated using vector algebra and shown as a black line in Fig. 9.

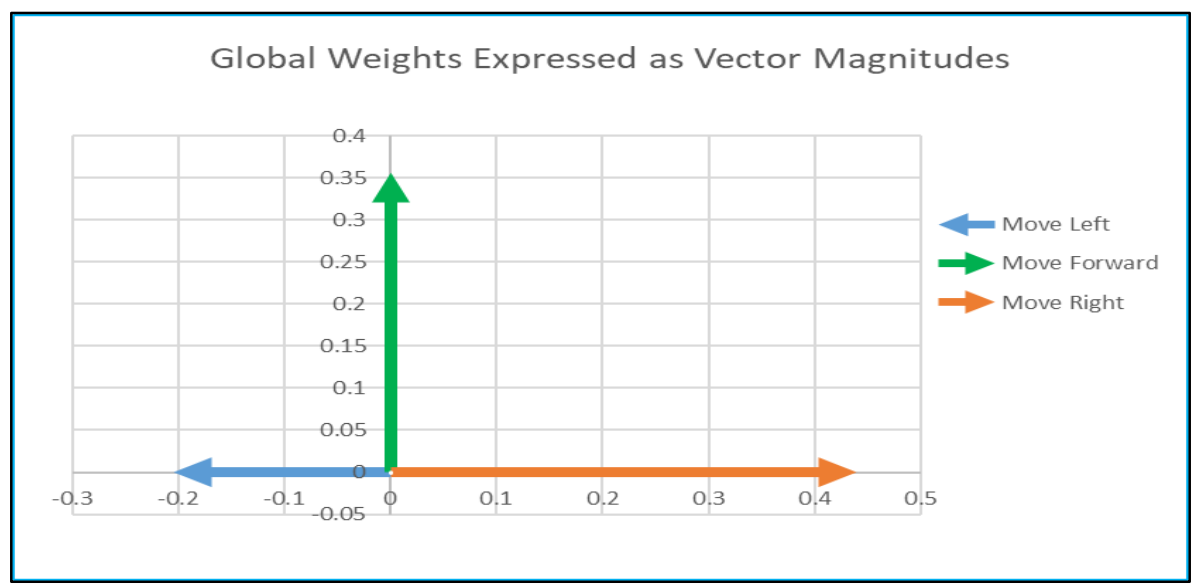

Fig. 8. Global scores of choices expressed as vector magnitudes, Setup 3: box sensed to the left. 


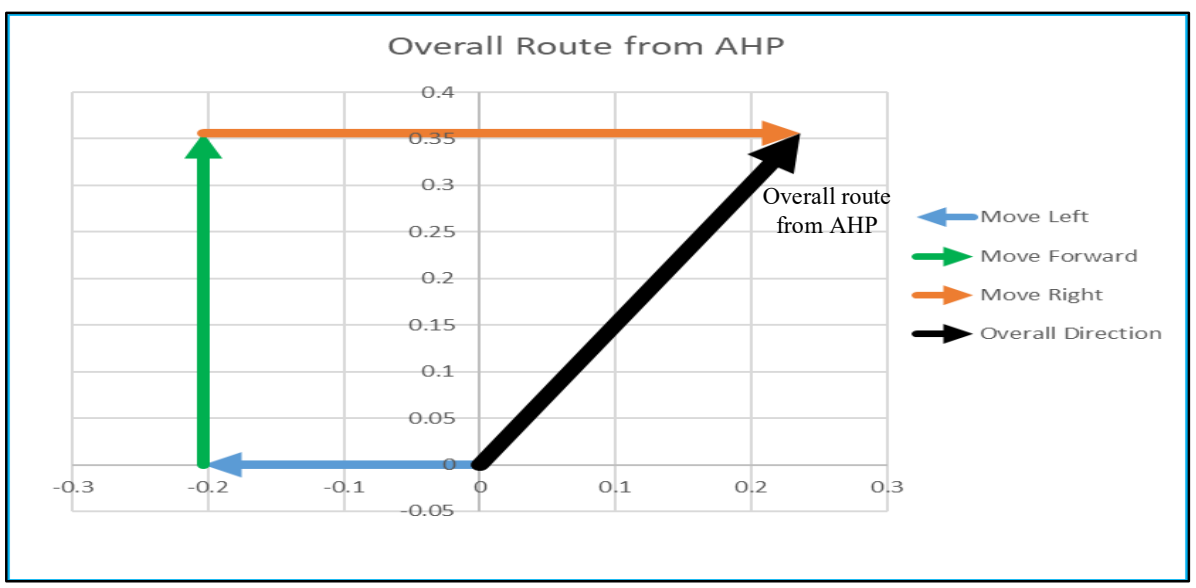

Fig. 9. Overall route yielded from AHP for Setup 3.

Sensitivity analysis was applied to assess the stability of AHP results if risk and uncertainty would affect criteria weights. The smallest changes needed to alter the results were evaluated. Results are shown in Table 4 where N/F stands for a nonfeasible value where $\pm 100 \%$ modification to a criterion value did not alter the result.

Table 4. Minimum percentage change in criteria weights needed to change the outcome of AHP, setup 3: 1 box sensed to the left.

\begin{tabular}{cl}
\hline Criterion name & Minimum percentage change \\
\hline$D_{1}$ & $\mathrm{~N} / \mathrm{F}$ \\
$\mathrm{D}_{\mathrm{c}}$ & $\mathrm{N} / \mathrm{F}$ \\
$\mathrm{D}_{\mathrm{r}}$ & $25.7 \%$
\end{tabular}

Sensitivity analysis identified the effect of change in $D_{r}, D_{c}$ and $D_{1}$ on the overall route of the wheelchair. A $400.01 \%$ rise in $D_{1}$, a $188.97 \%$ rise in $D_{c}$ or a $25.7 \%$ rise in $D_{r}$ caused the wheelchair to drive right and forward with an angel of $46^{\circ}$.

\section{Discussion}

The new system successfully presented a new approach to mix the desired direction provided by wheelchair driver with output form ultrasonic sensors. Poweredwheelchair drivers controlled their chairs using joysticks and sensors adjusted their route if required. Sensors systems provided a safe route for the wheelchair.

The output that control the wheelchair motor was a function of output from the decision-making system and the weighted desire of the user. $\mathrm{C}_{\text {comd }}$ (the overall control command) was derived using (6):

$$
C_{\text {comd }}=\left(G_{h}|J|+k_{t} C_{\text {sens }}\right)
$$


Where $G_{h}|\mathrm{~J}|$ is the joystick command, $\mathrm{C}_{\text {sens }}$ is the decision-making output and $\mathrm{k}_{\mathrm{t}}$ was an increasing variable (increasing over time) so the user can override the decisionmaking output.

Fig.10 shows the overall route for the wheelchair when mixing the output from AHP for setup 1when the user wanted to move to the left with a high speed. The line shown in black was the AHP output, the line shown in grey was the user desire and the line shown in red was the overall actual route and velocity.

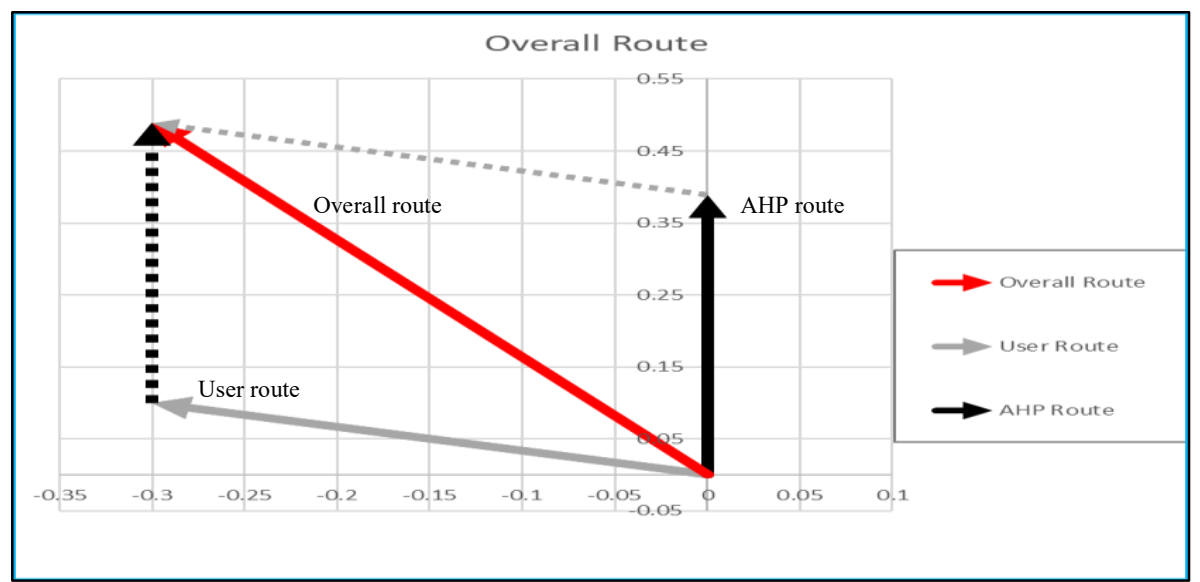

Fig. 10. Overall route of the Wheelchair after mixing AHP route for setup 1 and User desired route.

Fig. 11 shows the overall wheelchair route for setup 2, when the user wanted to move forward at a low speed. Fig. 12 shows the overall route of the wheelchair for setup 3 when the user wanted to move to the right at a moderate speed.

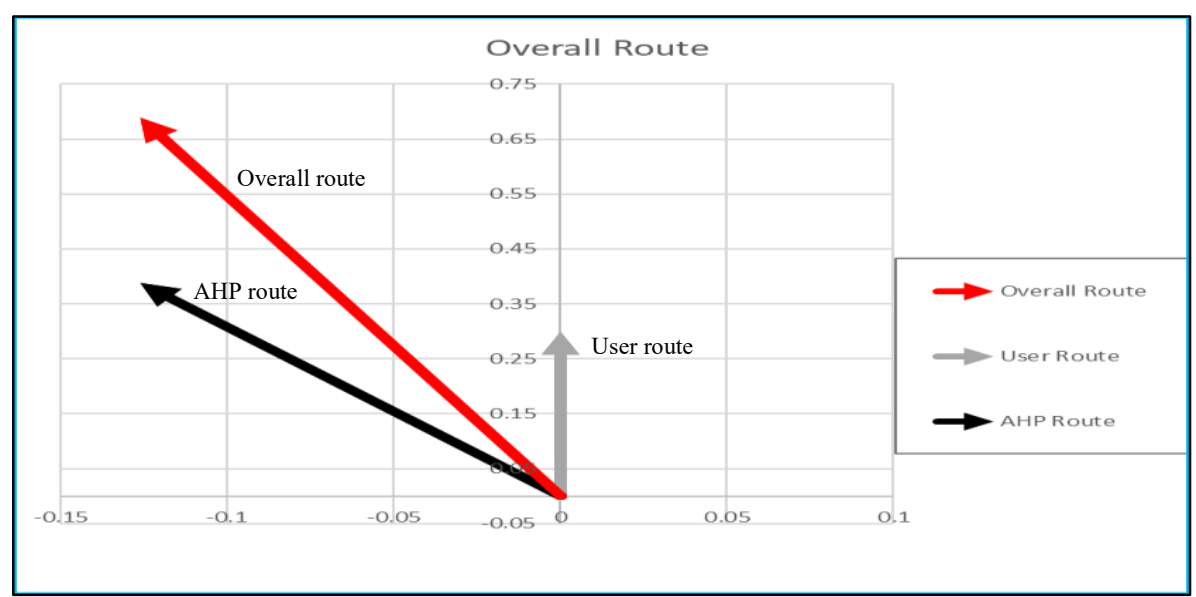

Fig. 11. Overall route of the Wheelchair after mixing AHP route for setup 2 and user desired route. 


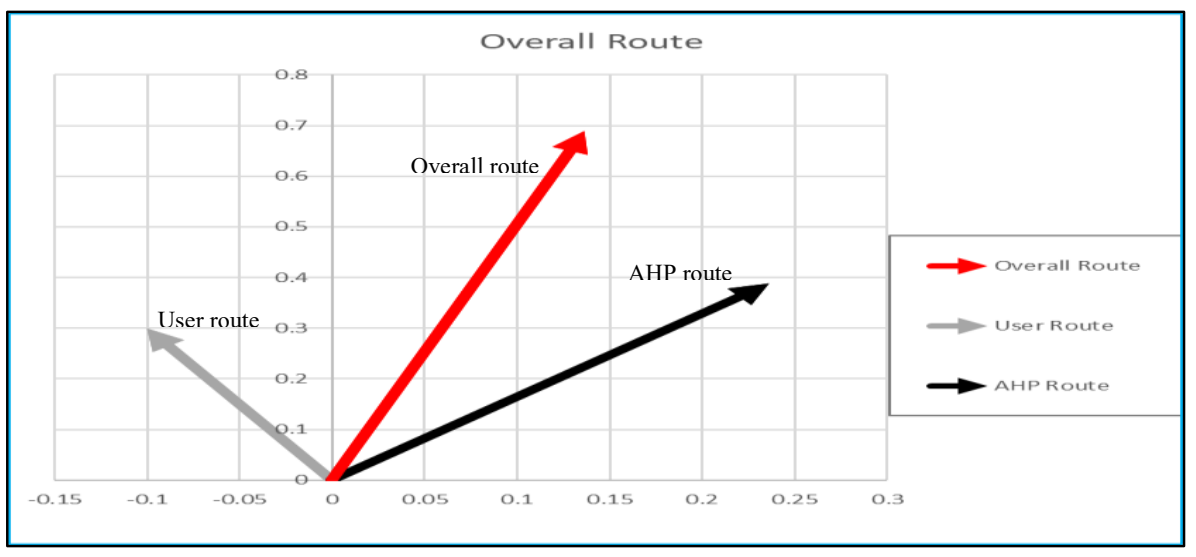

Fig. 12. Overall route of the Wheelchair after mixing AHP route for setup 3 and user desired route.

\section{Conclusions}

The research described in this paper effectively used AHP to avoid collisions. Mathematically inexpensive, effective and safe outcomes were accomplished. The new system provided support to wheelchair drivers while driving their wheelchairs as obstructions appeared in their path and wheelchairs were driven safely round them.

The work could bring some independence and decrease the need for helpers.

The authors are now considering new methods for the system to analyze additional inputs by integrating various AI techniques [2, 29, $35 \& 36]$. The general idea will be that multiple AI techniques can be applied to their maximum advantage.

MCDM could not consider all situations so neuro, reinforcement or neuro-fuzzy learning could deliver efficient outcomes. These algorithms will be explored.

Systems attempted to avoid obstacles but if a driver continuously indicated they desired to drive towards to a specific direction then the driver wishes could rule against the decision-making system. Driver wishes could rule against the system by holding a joystick in a fixed position. The chair drove as anticipated by the driver if nothing was sensed.

The authors are currently applying the AHP and Preference Ranking Organization MEthod for Enrichment of Evaluation (PROMETHEE) method to other problems. A framework for the intelligent selection of MCDM methods has been created [37].

The authors are applying different MCDM methods to different types of problems [38-41]. Future work will consider a bigger set of choices to consider $360^{\circ}$ around the chair. Uncertainty will be captured using probability functions, fuzzy set theory and percentages.

Results show that the decision-making system worked properly. Systems will be clinically trialed at Chailey Heritage as part of an ERSPC funded project [42]. Research is now examining path modification [43], force sensing [44] and contrasting accomplishments both with the sensors and without sensors [45]. 


\section{Acknowledgment}

Research in this paper was funded by EPSRC grant EP/S005927/1 and supported by The Chailey Heritage Foundation and the University of Portsmouth.

\section{References}

1. Parhi, D. R. and Singh, M. K.: Rule-based hybrid neural network for navigation of a wheelchair, Proc. IMechE Part B: J. Engineering Manufacture, 224, 11103 - 1117, (2009).

2. Sanders, D. A. Gegov, A. and Ndzi, D.: Knowledge-based expert system using a set of rules to assist a tele-operated mobile robot, in Studies in Computational Intelligence, (eds) Y. Bi, S. Kapoor, and R. Bhatia, 2018, 751, Springer, 2018b, pp. 371-392.

3. Sanders, D. A. et al.: Rule-based system to assist a tele-operator with driving a mobile robot. Lecture Notes in Networks and Systems, 16, Springer, pp. 599-615, 2018.

4. Sanders, D, Langner, M, Bausch, N, Huang, Y, Khaustov, SA \& Simandjuntak, S 2019, Improving human-machine interaction for a powered wheelchair driver by using variable-switches and sensors that reduce wheelchair-veer. in Y BI, R Bhatia \& S Kapoor (eds), Advances in Intelligent Systems and Computing, vol. 1038, Springer, pp. 1173-1191.

5. Okonor, OM, Gegov, A, Adda, M, Sanders, D, Haddad, MJM \& Tewkesbury, G 2019, Intelligent approach to minimizing power consumption in a cloudbased system collecting sensor data and monitoring the status of powered wheelchairs. in Y Bi, R Bhatia \& S Kapoor (eds), Advances in Intelligent Systems and Computing, vol. 1037, Springer, pp. 694-710.

6. Sanders, D, Okonor, OM, Langner, M, Hassan Sayed, M, Khaustov, SA \& Omoarebun, PO 2019, Using a simple expert system to assist a powered wheelchair user. in Y Bi, R Bhatia \& S Kapoor (eds), Advances in Intelligent Systems and Computing, vol. 1037, Springer, pp. 662-379.

7. Bausch, N, Shilling, P, Sanders, D, Haddad, MJM, Okonor, OM \& Tewkesbury, G 2019, Indoor location and collision feedback for a powered wheelchair system using machine learning. Advances in Intelligent Systems and Computing, Springer, IEEE SAI Intelligent Systems Conference 2019, London, United Kingdom, 5/09/19, Vol. 1 pp. 721-739.

8. Tewkesbury, G, Sanders, D, Haddad, MJM, Bausch, N, Gegov, A \& Okonor, OM 2019, Task programming methodology for powered wheelchairs. Advances in Intelligent Systems and Computing, Springer, IEEE SAI Intelligent Systems Conference 2019, London, United Kingdom, 5/09/19, Vol. 1 pp. 711-720.

9. Sanders, D, Tewkesbury, G, Parchizadeh, H, Robertson, JJ, Omoarebun, PO \& Malik, M 2019, Learning to drive with and without intelligent computer systems and sensors to assist. in K Arai, S Kapoor \& R Bhatia (eds), Advances in Intelligent Systems and Computing, vol. 868, Springer, pp. 1171-1181. 
10. Sanders, D, Gegov, A, Haddad, M, Ikwan, F, Wiltshire, D \& Tan, YC 2019, A rule-based expert system to decide on direction and speed of a powered wheelchair. in K Arai, S Kapoor \& R Bhatia (eds), Advances in Intelligent Systems and Computing, vol. 868, Springer, pp. 822-838.

11. Haddad, M, Sanders, D, Bausch, N, Tewkesbury, G, Gegov, A \& Hassan Sayed, M 2019, Learning to make intelligent decisions using an Expert System for the intelligent selection of either PROMETHEE II or the Analytical Hierarchy Process. in K Arai, S Kapoor \& R Bhatia (eds), Advances in Intelligent Systems and Computing, vol. 868, Springer, pp. 1303-1316.

12. Parhi D. R. et al.: "The stable and precise motion control for multiple wheelchairs", Appl. Soft Comput, 9(2), 477 - 487, (2009).

13. Nguyen, V. et al.: Strategies for Human - Machine Interface in an Intelligent Wheelchair, 35th Annual Int Conf of IEEE- (EMBC), Osaka, JAPAN. Book Series: IEEE Engineering in Medicine \& Biology Society Conf Proceedings, 2013, pp. 3638-3641.

14. Haddad, MJM, Sanders, D, Gegov, A, Hassan Sayed, M, Huang, Y \& AlMosawi, M 2019, Combining multiple criteria decision making with vector manipulation to decide on the direction for a powered wheelchair. in $\mathrm{Y} \mathrm{Bi}, \mathrm{R}$ Bhatia \& S Kapoor (eds), Advances in Intelligent Systems and Computing, vol. 1037, Springer, pp. 680-693, .

15. Haddad, MJM, Sanders, D, Tewkesbury, G, Gegov, A, Hassan Sayed, M \& Ikwan, FC 2019, Initial results from using Preference Ranking Organization METHods for Enrichment of Evaluations to help steer a powered wheelchair. in Y Bi, R Bhatia \& S Kapoor (eds), Advances in Intelligent Systems and Computing, vol. 1037, Springer, pp. 648-661.

16. Sanders, D, Wang, Q, Bausch, N, Huang, Y, Khaustov, SA \& Popov, I 2019, A method to produce minimal real time geometric representations of moving obstacles. in K Arai, S Kapoor \& R Bhatia (eds), Advances in Intelligent Systems and Computing, vol. 868, Springer, pp. 881-892.

17. Sanders, D, Gegov, A, Tewkesbury, G \& Khusainov, R 2019, Sharing driving between a vehicle driver and a sensor system using trust-factors to set control gains. in K Arai, S Kapoor \& R Bhatia (eds), Advances in Intelligent Systems and Computing, vol. 868, Springer, pp. 1182-1195.

18. Sanders, D. A. et al.: Results from investigating powered wheelchair users learning to drive with varying levels of sensor support, in Proc SAI Intelligent System, London, U.K. 2017, pp.

19. Song, K. T. and Chen, C. C.: Application of asymmetric mapping for wheelchair navigation using ultrasonic sensors, J. Intell. Wheelchair Syst., 17(3), 243 - 264, (1996).

20. Sanders, D., Langner, M. and Tewkesbury, G.: Improving wheelchair- driving using a sensor system to control wheelchair-veer and variable-switches as an alternative to digital-switches or joysticks, Ind Rob: An int' jnl, 37(2), 151167, 2010.

21. Lee, S.: Use of infrared light reflecting landmarks for localization, Ind Rob: An int' jnl, 36,(2), 138-145, (2009). 
22. Sanders, D. and Stott, I.: A new prototype intelligent mobility system to assist powered wheelchair users, Ind Rob, 26(6), 466-475, (2009).

23. Larsson, J., Broxvall, M. and Saffiotti, A.: Laser-based corridor detection for reactive Navigation, Ind Rob: An int' jnl, 35(1), 69-79, (2008).

24. Milanes, V., Naranjo, J. and Gonzalez, C.: Autonomous vehicle based in cooperative GPS and inertial systems, Robotica, 26, 627-633, (2008).

25. Sanders, D. A.: Controlling the direction of walkie type forklifts and pallet jacks on sloping ground. Assem. Autom., 28(4), 317-324, (2008).

26. Sanders, D.: Recognizing shipbuilding parts using artificial neural networks and Fourier descriptors, Proceedings of the Institution of Mechanical Engineers - Part B- Journal of Engineering Manufacture, 223(3), 337-342, (2009)a.

27. Chang, Y. C. and Yamamoto, Y.: On-line path planning strategy integrated with collision and dead-lock avoidance schemes for wheeled wheelchair in indoor environments, Ind Rob: An int' jnl, 35(5), 421-434, (2008).

28. Sanders, D.: Comparing speed to complete progressively more difficult mobile robot paths between human tele-operators and humans with sensorsystems to assist, Assem. Autom., 29(3), 230-248, (2009)b.

29. Ishizaka, A. and Siraj, S.: Are multi-criteria decision-making tools useful? An experimental comparative study of three methods, EJOR, 264, 462-471, (2018).

30. Sanders, D. A.: Using self-reliance factors to decide how to share control between human powered wheelchair drivers and ultrasonic sensors, IEEE Transactions on Neural Systems and Rehabilitation Engineering, 25(8), 12211229, (2017).

31. Sanders, D. A. et al.: Tele-operator performance and their perception of system time lags when completing mobile robot tasks, Proc 9th Int Conf on Human Systems Interaction, 2016, pp. 236-242.

32. Raju, K. and Kumar, D.: Irrigation Planning using Genetic Algorithms, Water Resource Management, 18, 163 - 176, (2004).

33. Haddad, M., Sanders, D. and Bausch, N.: Selecting a Robust Decision Making Method to Evaluate Employee Performance, International Journal of Management and Decision Making. 8(4),333 -351, (2019).

34. Saaty, T. L.: Decision making with the analytic hierarchy process, International journal of services sciences, 1(1), 83-98, (2008).

35. Ishizaka, A. and Labib, A.: Analytic hierarchy process and expert choice: Benefits and limitations, Or Insight, 22(4), 201-220, (2009).

36. Gegov, A., Gobalakrishnan, N.and Sanders, D. A.: Rule base compression in fuzzy systems by filtration of non-monotonic rules, Journal of Intelligent \& Fuzzy Systems, 27(4), 2029-2043, (2014).

37. Sanders, D. A. et al.: A Rule-based Expert System to decide on direction and speed of a powered wheelchair. IEEE Proceedings of the SAI Conference on IntelliSys. London, U.K., 2018a, pp. 426 - 433. 
38. Haddad, M. and Sanders, D.: The Behavior of Three Discrete Multiple Criteria Decision Making Methods in the Presence of Uncertainty, Operations Research Perspectives, to be published.

39. Haddad, MJM, Sanders, D \& Bausch, N 2019, 'Selecting a robust decision making method to evaluate employee performance', International Journal of Management and Decision Making, vol. 18, no. 4, pp. 333-351.

40. Haddad, MJM \& Sanders, D 2019, 'Selecting a best compromise direction for a powered wheelchair using PROMETHEE', IEEE Transactions on Neural Systems and Rehabilitation Engineering, vol. 27, no. 2, pp. 228-235. https://doi.org/10.1109/TNSRE.2019.2892587

41. Sanders, D, Robinson, DC, Hassan Sayed, M, Haddad, MJM, Gegov, A \& Ahmed, N 2019, Making decisions about saving energy in compressed air systems using Ambient Intelligence and Artificial Intelligence. in K Arai, S Kapoor \& R Bhatia (eds), Advances in Intelligent Systems and Computing, vol. 869, Springer, pp. 1229-1236.

42. Sanders, D. and Gegov, A.: Using artificial intelligence to share control of a powered-wheelchair between a wheelchair user and an intelligent sensor system, EPSRC Project 2019 - 2022, (2018).

43. Sanders, D. A.: The modification of pre-planned manipulator paths to improve the gross motions associated with the pick and place task. ROBOTICA, 13, 77-85. (1995).

44. Sanders, D. A.: Viewpoint - Force sensing. Industrial Robot, 34, 177. (2007).

45. Sanders, D.: Comparing ability to complete simple tele-operated rescue or maintenance mobile-robot tasks with and without a sensor system. Sensor Review, 30(1), 40-50. (2010). 